\title{
TEORIA DE FLORENCE NIGHTINGALE: APROXIMAÇÕES REFLEXIVAS NO CONTEXTO DA PANDEMIA DA COVID-19
}

Diego Schaurich ${ }^{1}$ Oclaris Lopes Munhoz ${ }^{1}$ Angélica Dalmolin ${ }^{1}$ https://orcid.org/0000-0002-6935-5382 https://orcid.org/0000-0001-8901-7148 https://orcid.org/0000-0002-0595-1054

Objetivo: refletir acerca das contribuições da Teoria Ambientalista de Florence Nightingale e aproximá-las das recomendações de prevenção e controle à Covid-19. Método: ensaio de natureza teórico-reflexiva, desenvolvido em maio e junho de 2020, à luz da Teoria Ambientalista de Florence Nightingale. Resultados: desvelou-se dois eixos temáticos, quais sejam: Aproximações entre a Teoria Ambientalista e a Organização do Cuidado ao Paciente Hospitalizado com Covid-19; e, Aproximações entre a Teoria Ambientalista e as Medidas de Prevenção e Controle à Covid-19 na Comunidade. Conclusões: no contexto da pandemia da Covid-19, os postulados de Florence em relação aos ambientes salubres, iluminados, arejados e sobre a necessidade de higiene, separação dos mais adoecidos e de organização do cuidado reforçam a importância de suas contribuições para a ciência da enfermagem, para a prevenção de doenças e para um cuidado adequado e integral aos adoecidos.

Descritores: Enfermagem; Teoria de enfermagem; Infecções por coronavírus; Vírus da SARS; Saúde pública.

\section{FLORENCE NIGHTINGALE THEORY: REFLECTIVE APPROACHES IN THE COVID-19 PANDEMIC CONTEXT}

Objective: to reflect on the contributions of Florence Nightingale's Environmental Theory and bring them closer to the prevention and control recommendations to Covid-19. Method: theoretical-reflective essay, developed in May and June 2020, in the light of Florence Nightingale's Environmental Theory. Results: two thematic axes were unveiled, namely: Approximations between the Environmental Theory and the Organization of Care for Hospitalized Patients with Covid-19; and, Approximations between Environmental Theory and Covid-19 Prevention and Control Measures in the Community. Conclusions: in the context of the Covid-19 pandemic, Florence's postulates in relation to healthy, light, airy environments and the need for hygiene, separation of the most sick and care organization reinforce the importance of their contributions to the science of nursing, for disease prevention and for adequate and comprehensive care for the sick.

Descriptors: Nursing; Nursing theory; Coronavirus infections; SARS Virus; Public health.

\section{TEORÍA DE LA FLORENCE NIGHTINGALE: APROXIMACIONES REFLEXIVOS EN EL CONTEXTO PANDÉMICO DE COVID-19}

Objetivo: reflexionar sobre las contribuciones de la teoría ambiental de Florence Nightingale y acercarlas a las recomendaciones de prevención y control de Covid-19. Método: ensayo teórico-reflexivo, desarrollado en mayo y junio de 2020 , a la luz de la teoría ambiental de Florence Nightingale. Resultados: se revelaron dos ejes temáticos, a saber: aproximaciones entre la teoría ambiental y la organización de atención para pacientes hospitalizados con Covid-19; y, Aproximaciones entre la teoría ambiental y las medidas de prevención y control de Covid-19 en la comunidad. Conclusiones: en el contexto de la pandemia de Covid-19, los postulados de Florencia sobre ambientes saludables, luminosos y ventilados y la necesidad de higiene, la separación de los más enfermos y de la organizacion de cuidados refuerzan la importancia de sus contribuciones a la ciencia de enfermería, para la prevención de enfermedades y para una atención adecuada e integral para los enfermos.

Descriptores: Enfermería; Teoría de enfermería; Infecciones por coronavirus; Virus del SRAS; Salud pública.

Universidade Federal de Santa Maria, Santa Maria, RS, Brasil.

Autor Correspondente: Diego Schaurich E-mail: eu_diegosch@hotmail.com

Recebido: 29/6/20 Aceito: 30/7/20 


\section{INTRODUÇÃO}

Recentemente, um surto de pneumonia relacionada a uma nova espécie de coronavírus passou a preocupar órgãos e instituições de saúde a nível mundial, haja vista seu potencial de disseminação e contágio. Os primeiros casos foram constatados em dezembro de 2019, na cidade de Wuhan, na China $^{1}$, e em pouco mais de um mês do seu surgimento, a Organização Mundial da Saúde (OMS) definiu essa situação como uma Emergência de Saúde Pública e de interesse internacional, resultado do aumento rápido e expressivo no número de pessoas infectadas. Em março de 2020, a OMS caracterizou o cenário atual como uma pandemia ${ }^{1}$

Identificou-se que este novo patógeno é resultado de uma mutação da família dos coronavírus, sendo então definido como Severe Acute Respiratory Syndrome Coronavirus 2 (SARS-CoV-2), causador da doença Covid-19, a qual é responsável por ocasionar quadros clínicos respiratórios que podem variar de infecções assintomáticas a casos graves $^{2}$. Os principais sintomas são: febre, coriza, dor de garganta, tosse e dificuldade para respirar ${ }^{1}$. No entanto, nos casos mais críticos os pacientes podem evoluir para uma Síndrome Aguda Respiratória Grave, necessitando de cuidados intensivos ${ }^{1-2}$.

O SARS-CoV-2 é transmitido de uma pessoa contaminada para outra não contaminada (transmissão direta), bem como pelo contato com objetos e superfícies contaminados com o vírus (transmissão indireta), sendo as gotículas de saliva seu principal meio de disseminação². Dentre às medidas preventivas e protetivas à Covid-19, tem-se o uso de máscaras, a etiqueta respiratória, a higienização rotineira das mãos, a manutenção de ambientes limpos e arejados, a necessidade de evitar aglomerações e o isolamento de pacientes contaminados ${ }^{1}$

Ao estabelecermos uma relação entre o atual cenário mundial e o contexto histórico de reconhecimento, controle e prevenção de doenças é possivel perceber que as medidas de prevenção e controle ao novo coronavírus, de certa forma, aproximam-se aos postulados da enfermeira Florence Nightingale. Em 1854, durante a Guerra da Criméia, Florence percebera que o desfecho clínico dos pacientes era diretamente influenciado pelo ambiente em que os cuidados eram prestados. Dessa forma, a higiene e os aspectos sanitários do local constituem-se em elementos determinantes para as condições de saúde das pessoas atendidas ${ }^{3-4}$

A partir disso, ela evidenciou que uma das formas de reduzir o número de mortes de seus pacientes perpassava pela necessidade de tornar os ambientes de internação salubres, com circulação de ar, luz e limpeza, assim como a organização do cuidado; ou seja, a melhora clínica de um pa- ciente estava intimamente relacionada a gestão das condições do (meio) ambiente ${ }^{5}$. Embora sem recursos adequados, Florence desenvolveu seus próprios métodos de trabalho, utilizando os conhecimentos adquiridos nas experiências pregressas, as habilidades e as vivências práticas para gerir a administração e a organização hospitalar, na constituição da Enfermagem Moderna e na formação de um modelo educacional.

Com um pensamento aguçado e perspicaz para a época, fruto de sua educação aristocrática que lhe permitiu estudar vários idiomas, matemática, religião e filosofia, Nightingale tinha uma visão ampliada e singular sobre o cuidado, a qual subsidiou as bases científicas que fundamentam a ciência da Enfermagem ${ }^{6}$. Assim, considerando suas exitosas contribuições, faz-se mister investir em publicações que apresentem reflexões acerca da utilização da Teoria Ambientalista na prática clínica da enfermagem, uma vez que estas são relevantes e atuais ao considerarmos o contexto da Covid-19, permitindo consolidar os conhecimentos específicos da disciplina e salientar o protagonismo da Enfermagem face a esta pandemia

Ante ao exposto, propõe-se tecer aproximações reflexivas entre o legado da Teoria Ambientalista de Florence Nightingale e as atuais discussões relacionadas ao novo coronavírus, considerando os ambientes hospitalar e comunitário. Assim sendo, objetiva-se refletir acerca das contribuições da Teoria Ambientalista de Florence Nightingale e aproximá-las das recomendações de prevenção e controle à Covid-19.

Teoria Ambientalista de Florence Nightingale: breves considerações

Os postulados escritos a partir das vivências, experiências e conhecimentos de Florence Nightingale auxiliaram a subsidiar e fundamentar o que hoje reconhecemos como Enfermagem Moderna, e sustentam o que se passou a considerar a primeira teoria de enfermagem: a Teoria Ambientalista ${ }^{7}$. Assim, tendo como eixo principal o conceito de ambiente envolvido no processo de saúde-doença, Florence trouxe à luz elementos essenciais que compõem o cotidiano de vida dos indivíduos, tanto no cenário hospitalar como no comunitário, e que apresentam correlação direta com a saúde ou o adoecimento das pessoas.

Mesmo anterior à aceitação geral da teoria dos germes, este modelo teórico de enfermagem já considerava que "a limpeza, o ar fresco, os aspectos sanitários, o conforto e a socialização eram necessários para a cura"8:15. Portanto, entende-se que Florence, a partir da confluência de saberes oriundos de outras áreas do conhecimento, como estatística, saúde pública, espiritualidade e administração, demons- 
trou, dedutivamente, as relações que existem entre os indivíduos e o meio a que pertencem e interagem, trazendo contribuições à tríade saúde-cuidado-cura.

Para Florence, o ser humano é um ser integrante da natureza e possuidor de um poder vital, capaz de agir sobre sua própria recuperação, restaurando seu bem-estar e sua saúde. $O$ meio ambiente foi por ela definido como tudo aquilo que cerca ou que envolve os seres vivos, sendo as condições externas que exercem influência na vida e no desenvolvimento das pessoas, favorecendo meios de prevenção e contribuindo para a saúde ou para a doença $a^{3,7}$.

Saúde foi considerada por Florence como algo amplo, que transcende a consciência de se estar bem em razão da não percepção de uma doença, mas como uma possibilidade de usar adequadamente todos os recursos disponíveis, sejam eles pessoais ou condições fornecidas pelo meio ambiente, a fim de viver de forma (mais) saudável. A enfermagem, por sua vez, tem o intuito de auxiliar na manutenção das capacidades vitais e possibilitar ao ser humano melhores condições para satisfazer suas necessidades, por meio do cuidado de pessoas sadias e doentes, recorrendo ao meio ambiente como uma possibilidade de potencializar um viver saudável ${ }^{3}$.

A partir destas compreensões, entende-se que o foco do cuidado de enfermagem segundo as concepções da Teoria Ambientalista deve estar voltado para a higiene e manutenção do meio ambiente em que o indivíduo está inserido. Para tanto, Florence elencou alguns fatores do meio ambiente que agem sobre a saúde do ser humano, os quais devem ser considerados no cuidado da enfermagem: arejamento e aquecimento, ruídos, iluminação, variedades, alimentação, limpeza de quartos e paredes, higiene pessoal e condições sanitárias das moradias ${ }^{4,6}$

Em seu entendimento, existem cinco elementos essenciais para um ambiente (hospitalar ou residencial) saudável e promotor da saúde, quais sejam: ar e água puros, luz, limpeza e drenagem eficiente ${ }^{3}$. Em suas anotações ela esclarece que uma das primeiras regras da enfermagem é manter o ambiente interno com o ar tão puro quanto o ambiente externo, recomendando, na medida do possivel, a abertura de janelas, em especial à noite, para aproveitar o silêncio. Ainda, salienta que, para prevenir infecções e preservar um ambiente saudável, é fundamental a sua limpeza e higienização.

Além disso, destaca que uma boa iluminação do ambiente é indispensável, pois favorece o cuidado aos necessitados, facilita as medidas de limpeza e dificulta o surgimento de doenças ${ }^{3}$. Os ruídos, por sua vez, devem ser evitados ao máximo, sejam eles intencionais ou não; de acordo com Florence, um ruído desnecessário é mais prejudicial que um ba- rulho inevitável, mesmo que este seja maior e mais intenso ${ }^{7}$.

Por fim, o conforto dos pacientes hospitalizados é considerado determinante para restabelecer a saúde, o qual deve ser vislumbrado a partir das seguintes perspectivas: alimentação (horários das refeições, auxílio na sua administração, higiene dos alimentos, qualidade da dieta), cama e roupas de cama (camas distantes uma das outras e próximas de janelas, limpeza das roupas de cama, lençóis trocados com frequência e sem dobras) e boa manutenção da pele (banhos diários com água e sabão, e troca de roupas dos pacientes).

\section{MÉTODO}

Trata-se de uma produção teórico-reflexiva, desenvolvida entre maio e junho de 2020, embasada na Teoria Ambientalista de Florence Nightingale, associada às experiências dos autores e às recomendações de órgãos oficiais de saúde frente a pandemia da Covid-19. Buscou-se discutir acerca do impacto da pandemia nos cuidados prestados ao paciente hospitalizado, bem como sobre o controle e a prevenção da disseminação do novo coronavírus na comunidade, pautando-se em aproximações reflexivas com os postulados de Florence.

\section{Eixos reflexivos e discussão}

Aproximações entre a Teoria Ambientalista e a Organização do Cuidado ao Paciente Hospitalizado com Covid-19

A necessidade de organização e gerenciamento do cuidado está entre as observações feitas por Florence ${ }^{3}$. No contexto da pandemia, percebe-se que o mundo precisou perpassar (e ainda perpassa) por significativas modificações relacionadas à reorganização da assistência aos adoecidos. Repentinamente, as instituições de saúde necessitaram adaptar-se à essa realidade, criando unidades específicas de atendimento aos pacientes com Covid-19, recrutando mais trabalhadores de saúde e de apoio, aumentando a compra de insumos e alterando abruptamente suas rotinas de trabalho.

O avanço do novo coronavírus tem trazido diversas implicações e desafios aos serviços e ao cuidado em saúde, bem como aos profissionais, em especial, aos da enfermagem. Em um curto período de tempo - a se considerar os primeiros casos em Wuhan, até a sua chegada ao território brasileiro (aproximadamente, dois meses) -, profissionais, pesquisadores, cientistas e gestores de políticas públicas precisaram planejar, desenvolver, rever, adaptar e instituir normas, procedimentos, rotinas, infraestrutura e logística que pudessem, em uma tentativa organizada e coordenada, dar conta da pandemia e de suas consequências, estabelecendo verdadeiramente uma luta contra o relógio?

As instituições de saúde precisaram recrutar e capa- 
citar profissionais de saúde para atuarem a nível de cuidados intensivos e críticos, assim como reordenar os fluxos e protocolos internos de atendimento, com vistas a oferecer um cuidar que levasse em consideração, no mínimo, duas perspectivas: a proteção destes profissionais - inclusive em aspectos de incentivo ao autocuidado e ao cuidado de seus familiares - e o cuidado humanizado e personalizado aos pacientes internados com Covid-19. Pode-se, assim, de maneira análoga, mas mantendo as devidas limitações comparativas, considerar que estas ações atuais refletem as lógicas propostas e implementadas por Florence Nightingale, principalmente, na Guerra da Criméia ${ }^{3}$.

No entanto, ao considerar um cenário epidêmico, a organização do cuidado e das instituições de saúde, defendida por Florence, fica desafiada, uma vez que se vivencia a superlotação das unidades hospitalares, a falta de recursos materiais e de trabalhadores especializados em vista da necessidade de criação de novos leitos de terapia intensiva. Tais problemas e dificuldades laborais influenciam negativamente na saúde dos trabalhadores e dos pacientes que deles necessitam, assim como na qualidade do cuidado prestado ${ }^{10}$.

Sabe-se, ainda, que o cuidado ao paciente hospitalizado acometido pela Covid-19 perpassa por uma série de medidas de higiene, em especial das mãos, dos instrumentos utilizados para prestar assistência e do local onde se encontram os pacientes e trabalhadores. Essas medidas fortalecem as proposições de Florence no que tange à necessidade de eliminar germes e manter o ambiente limpo, com vistas a diminuir os novos casos de infecção, inclusive ressaltando a importância da lavagem constante das mãos ${ }^{3,6}$ por parte dos profissionais de saúde. No contexto de uma pandemia, essa higiene necessita ser reforçada, pois o SARS-CoV-2 é altamente infectante e de acelerada disseminação, culminando no aumento do quantitativo de trabalhadores responsáveis pela higienização e desinfeção, situação essa que pode ocasionar desgaste físico e laboral, haja vista a necessidade de repetição exaustiva das medidas de higiene ${ }^{11}$.

Outro aspecto relevante está relacionado ao processo de paramentação e desparamentação que é exigido aos profissionais, em especial os de enfermagem, por estarem 24 horas assistindo os adoecidos. O considerável número de EPIs necessários e a ordem dos processos requerem cautela, tendo em vista os pacientes com alta transmissibilidade viral e o receio pela contaminação. Ainda, em muitas realidades, não há equipamentos de proteção suficientes, fato que faz com que muitos profissionais comprem seu próprio material de proteção para poder trabalhar. Essa situação pode vir a gerar conflitos éticos e pessoais entre o prestar atendimento e o direito de negar-se, assim como pela necessidade de remuneração para seu sustento e de sua família, podendo gerar sofrimento moral no profissional ${ }^{12-13}$

Faz-se necessário salientar, também, a necessidade de um cuidado que leve em consideração que os indivíduos (pacientes e trabalhadores) sofrem influência, segundo $\mathrm{Ni}$ ghtingale, dos ambientes físico, social e psicológico ${ }^{7}$, os quais apresentam-se, muitas vezes, modificados frente a uma pandemia como a vivenciada atualmente ${ }^{14}$. Percebe-se que o ambiente físico e social do hospital se modificou, pois ocorreu uma restrição ainda maior na circulação de pessoas (em grande parte pelas medidas de proibição de visitantes), pelo cancelamento de procedimentos cirúrgicos eletivos, pelo fechamento de espaços coletivos destas instituições e, inclusive, pela menor procura por consultas e tratamentos de continuidade, como no caso de pacientes oncológicos e com doenças crônico-degenerativas.

Em relação ao ambiente psicológico, salienta-se que o longo período que os pacientes infectados pelo novo coronavírus permanecem internados, a dinâmica complexa de cuidados intensivos (entubação, diálise, etc.), os muitos casos de pacientes graves pela infecção e a restrição de visitação familiar são exemplos que podem elucidar os medos, os receios e as incertezas que acompanham os pacientes com Covid-19 e os profissionais de enfermagem, influenciando em suas saúdes mentais ${ }^{9}$. Ainda, destacam-se as preocupações dos profissionais inerentes ao próprio trabalho, ou seja, o aumento do número de horas de assistência (têm sido comum plantões de 12 a 24 horas contínuas), dificuldades na realização de suas necessidades básicas (alimentação, diurese, etc.) em virtude da restrita disponibilidade de EPIs e do tempo demandado para a paramentação/desparamentação, o medo de se infectarem em seus locais de atuação, entre outras ${ }^{13}$.

\section{Aproximações entre a Teoria Ambientalista e as Medidas} de Prevenção e Controle à Covid-19 na Comunidade

Para além dos aspectos inerentes às instituições de saúde, Florence também voltou seu olhar para a saúde nos espaços domiciliares e comunitários. Com experiências marcantes e exitosas junto à reforma sanitária da Índia e nas melhorias das condições de saúde do povo indígena da Austrália e das classes mais pobres e desfavorecidas da Inglaterra $^{7-8}$, Nightingale deixou seu legado para a proposição de cuidados e de políticas públicas que considerem o binômio saúde-natureza.

Quando nos referimos à comunidade diante da pandemia da Covid-19, tem-se como principal recomendação o isolamento físico social, em que se orienta que as pessoas permaneçam em casa para evitar que o SARS-CoV-2 se dis- 
semine, o que favorece o achatamento da curva de casos ${ }^{1}$. Entretanto, caso um indivíduo precise sair de casa, as autoridades recomendam o uso de máscara e evitar ambientes com aglomerações ${ }^{1}$, o que vêm ao encontro do pensamento de Florence, pois o controle da comunidade compõe seu enfoque para o enfrentamento de doenças ${ }^{6-7}$.

Contudo, ainda que seja recomendado o isolamento social, considera-se de suma importância a higiene com álcool 70\% ou água e sabão ${ }^{1}$ de todo e qualquer insumo/ objeto oriundo do ambiente externo à casa, já que o novo coronavírus, diferente de outros patógenos, permanece infeccioso por horas ou dias, a exemplo de sua persistência em superfícies de metal, plástico, vidro e papel, que pode perdurar por até cinco dias ${ }^{11}$, reforçando a necessidade de higienização. Assim, ao encontro do defendido por Florence, a casa onde vive uma família também necessita de adequada higienização, visto que se sabe que esses materiais fazem parte de sua rotina e refletem em seu bem-estar e na sua saúde.

Outro postulado importante defendido por Florence diz respeito ao arejamento dos ambientes, dos espaços comuns em que vivem os indivíduos, sendo que um cuidado redobrado deve ser dispensado aos domicílios. Para além das questões inerentes à limpeza dos objetos presentes nos espaços internos das residências, faz-se imprescindivel que estes locais estejam bem iluminados e ventilados, o que auxilia na circulação de ar e diminui as possibilidades de infecção pelo novo coronavírus. No entendimento de Florence, "a moradia deve permitir a entrada do ar externo igual para todos os cômodos. (...) Água quando não é pura e o esgoto mal canalizado são fontes de contaminação, levando à transmissão de doenças e epidemias"7:107

Entretanto, é importante despertar um olhar crítico, capaz de contemplar as mazelas que assolam a população brasileira, em especial àqueles que vivem em situação de vulnerabilidade social, muitas vezes, não desfrutando de condições mínimas para sua sobrevivência, a considerar a precariedade dos seus domicílios, a insalubridade loco-regional e a falta de saneamento básico. Sabe-se que o padrão de urbanização no Brasil agrava a distribuição desigual dos recursos sociais e de saúde, dificultando o acesso aos serviços entre os diversos grupos sociais dentro da sociedade ${ }^{15}$.

Considerando o exposto, encontram-se outros aspectos que são importantes quando se considera a disseminação de doenças, em especial as pandêmicas: o acesso a água de qualidade (tanto para o consumo, quanto para o uso em higiene e limpeza) e a cobertura domiciliar por serviço de saneamento básico. A cobertura de saneamento básico no Brasil é precária, com importantes diferenças e deficiências entre as regiões geográficas, bem como entre os municípios de um mesmo Estado, com reflexos de precariedade ainda mais desafiadores em localidades mais pauperizadas (como nas favelas e em bairros mais periféricos) e em regiões do Norte e Nordeste brasileiros ${ }^{16}$.

Mediante tais fatos, confrontamo-nos com dificuldades de implementar as proposições da Teoria Ambientalista, pois não se tem o mínimo e o essencial para assegurar a saúde e o bem-estar dessas pessoas, sendo necessário agir com efetividade face ao cenário atual a fim de amenizar as consequências, direcionando possibilidades de agir por meio de políticas públicas. Para mais, está posto na literatura científica que a desigualdade social associada a outros fatores pode condicionar a distribuição dos casos de uma nova doença ${ }^{15}$, contribuindo para a deflagração da pandemia de Covid-19

\section{Limitações do Estudo}

Por se tratar de uma produção teórico-reflexiva, não se explorou aspectos bibliométricos e estatísticos relacionados à pandemia de Covid-19, o que limitou possiveis comparações e generalizações ao cenário mundial, haja vista que as aproximações foram feitas considerando as especificidades da realidade nacional. Ainda, torna-se pertinente verificar as repercussões do novo coronavírus por meio de pesquisas de campo com vistas a constatar as implicações da Covid-19 na população e no sistema de saúde brasileiro.

Contribuição dos Autores: todos os autores contriburam em todas as fases do estudo.

\section{CONSIDERAÇÕES FINAIS}

Ao refletirmos acerca dos postulados de Florence Nightigale, percebemos que seu pensamento avançado para a época contribuiu, e ainda contribui, para o cuidado em saúde, seja em ambiente hospitalar ou na comunidade. No contexto da pandemia da Covid-19, suas considerações com relação aos ambientes salubres, iluminados, arejados e sobre a necessidade de higiene, de organização do cuidado e separação dos mais adoecidos, reforçam a importância de suas contribuições para a enfermagem, para a prevenção de doenças e para um cuidado adequado e integral.

Para mais, identifica-se que a Teoria Ambientalista é factível de aplicação na prática clínica da Enfermagem face a pandemia da Covid-19, sendo relevante implementar suas proposições relativas ao ser humano, ao ambiente e à saúde. Os elementos centrais da teoria contêm, portanto, conceitos fundamentais da disciplina, fortalecendo o desenvolvimento da ciência da Enfermagem. 


\section{REFERÊNCIAS}

1. Organização Mundial de Saúde (OMS). Folha informativa - COVID-19 (doença causada pelo novo coronavírus). 2020. Disponivel em: https:// www.paho.org/bra/index.php?option=com_ contentEview=article\&id=6101: covid19\&Itemid=875. Acesso em: 22 abr. 2020.

2. Chen Y, Liu Q, Guo D. Emerging coronaviruses: Genome structure, replication, and pathogenesis. $\mathrm{J}$ Med Virol [Internet]. 2020 [cited 2020 May 22]; 92(4):418-423. DOI: https://dx.doi.org/10.1002/ jmv. 25681 .

3. Nightingale F. Notas sobre enfermagem: o que é e o que não é. São Paulo: Cortez; 1989.

4. Medeiros ABA, Enders BC, Lira ALBC. Teoria Ambientalista de Florence Nightingale: uma análise crítica. Esc Anna Nery. 2015; 19(3):518-524.

5. Barbosa LBA, Motta ALC, Resck ZMR. International Council of Nurses (ICN). Notas de enfermagem: um guia para cuidadores na atualidade. Trad. Telma Ribeiro Garcia. Rio de Janeiro: Elsevier; 2010.

6. Bezerra CMB, Silva BCO, Silva RAR, Martino MMF Monteiro AI, Enders BC. Análise descritiva da teoria ambientalista de enfermagem. Rev. Enferm Foco [Internet]. 2018 [cited 2020 Jun 03]; 9(2):79-83.

7. Santana AP, Paixão CAP, Jesus MR. Teoria Ambientalista - Florence Nightingale. In: Braga CG, Silva JV (orgs.). Teorias de Enfermagem. 1. ed. São Paulo: Iátria; 2011. p. 105-116.

8. Wills EM. Grandes Teorias da Enfermagem Baseada nas Necessidades Humanas. In: McEwen M, Wills EM. Bases Teóricas para Enfermagem. 4. ed. Porto Alegre: ArtMed; 2015. p. 156-15.

9. Jackson D, Bradbury-Jones C, Baptiste D, Gelling L, Morin K, Neville S et al. Life in the pandemic: some reflections on nursing in the context of COVID-19. J Clin Nurs. 2020; 29:2041-2043.

10. Gallasch CH, Cunha ML, Pereira LAS, Silva-Junior JS. Prevenção relacionada à exposição ocupacional do profissional de saúde no cenário de COVID-19. Rev enferm UERJ. 2020; 28:e49596. Doi: http:// dx.doi.org/10.12957/reuerj.2020.49596

11. Kampf G, Todt T, Pfaender S, Steinmann E. Persistence of coronaviruses on inanimate surfaces and their inactivation with biocidal agents. J Hosp Infect [Internet]. 2020 [cited 2020 Jun 03]; 104(3):246-51. Disponivel em: https://dx.doi.org/10.1016/j. jhin.2020.01.022

12. Lunardi VL, Lunardi Filho, WD, Silveira RS, Silva PA, Mancia JR. Gestão de enfermagem e construção de ambientes éticos. Rev. Enferm Foco [Internet]. 2016 [cited 2020 Jun 18]; 7(3/4):41-45

13. Miranda FMA, Santana L de L, Pizzolato AC, Saquis LMM. Condições de trabalho e o impacto na saúde dos profissionais de enfermagem frente a Covid-19. Cogitare enferm. [Internet]. 2020 [cited 2020 Jun 17]; 25. Disponivel em: http://dx.doi. org/10.5380/ce.v25i0.72702.

14. Johnson MC, Saletti-Cuesta L, Tumas N. Emociones, preocupaciones y reflexiones frente a la pandemia del COVID-19 en Argentina. Ciência \& Saúde Coletiva. 2020; 25(Supl 1): 2447-2456.

15. Johansen IC, Carmo RL, Alves LC. Intraurban social inequality: implications for the dengue epidemic in Campinas, SP, in 2014. Cad. Metrop. [Internet]. 2016 [cited 2020 Jun 23]; 18(36):421-440. Disponivel em: https://www.scielo.br/pdf/cm/ v18n36/2236-9996-cm-18-36-0421.pdf.

16. Britto AL, Rezende SC. The public policy for urban water supply and sanitation services in Brazil: financialization, commodification and resistance perspectives. Cad. Metrop. [Internet]. 2017 [cited 2020 Jun 17]; 19(39): 557-581. Disponivel em: https://www.scielo.br/ scielo.php?script=sci_arttextEpid=S223699962017000200557\&lng=pt\&nrm=iso 